\title{
RNase $\mathrm{H} /$ oligonucleotide-directed mRNA purification (ROMP) of apoll mRNA
}

\author{
Clinton C.MacDonald ${ }^{+}$and David L.Williams* \\ Department of Pharmacological Sciences and Program in Molecular Biology, State University of New \\ York at Stony Brook, Stony Brook, NY 11794, USA
}

Received November 13, 1992; Revised and Accepted January 10, 1993

Using the estrogen-induced mRNA for apolipoprotein (apo) II (1), we have developed a method for RNase H/oligonucleotidedirected mRNA purification (ROMP). ROMP can be used in the rapid and complete purification of any polyadenylated mRNA for which the sequence of the $3^{\prime}$ untranslated region is known. We imagine this scheme would be of particular use in the examination of functional and structural aspects of mRNA metabolism such as the analysis of cap structures, methylation patterns, or associated mRNP proteins. Furthermore, ROMP can provide a simple and rapid alternative to hybrid-selection (2) for the identification of cloned cDNAs. For ROMP of the apoII mRNA, total polyadenylated mRNA was isolated by oligo(dT) cellulose chromatography. ApoII mRNA was then cleaved with RNase $\mathrm{H}$ directed by an apoII-specific oligodeoxynucleotide complementary to 14 nucleotides of the $3^{\prime}$ untranslated region of the mRNA adjacent to the poly(A) tail. Purified apoII mRNA was then isolated in the fraction which did not rebind oligo(dT) cellulose.

Step 1 (polyA ${ }^{+}$selection). Total RNA was prepared from livers of estrogen treated roosters (1). PolyA ${ }^{+}$mRNA was selected from $10 \mu \mathrm{g}$ of total rooster liver RNA by two cycles of selection on oligo(dT) cellulose in the presence of $0.5 \%$ SDS (3). RNA was applied to a $0.5 \mathrm{~mL}$ oligo(dT) cellulose column in buffer A $(10 \mathrm{mM}$ Tris $-\mathrm{HCl}, 0.4 \mathrm{M} \mathrm{NaCl}, 1 \mathrm{mM}$ EDTA, $0.5 \%$ SDS, pH 7.5), washed extensively in buffer B (buffer A containing $0.1 \mathrm{M} \mathrm{NaCl}$ ), and eluted in $3 \mathrm{~mL}$ of buffer $\mathrm{C}$ (buffer A lacking $\mathrm{NaCl}$ ). After heating at $68^{\circ} \mathrm{C}$ for 5 minutes, $5 \mathrm{M} \mathrm{NaCl}$ was added to the eluted RNA to $0.4 \mathrm{M}$, and chromatography was repeated. Eluted polyA ${ }^{+}$RNA was concentrated by ethanol precipitation.

Step 2 (oligo hybridization and RNase $H$ hydrolysis). Oligo V (5'-GTAACAACCAACAT-3') is complementary to nucleotides 646-659 of apoII mRNA (3). PolyA ${ }^{+}$liver mRNA was resuspended in $33.5 \mu \mathrm{L}$ containing $0.5 \mu \mathrm{g}$ oligo $\mathrm{V}, 0.2 \mathrm{M} \mathrm{NaCl}$, $5 \mathrm{mM} \mathrm{MgCl} 2,25 \mathrm{mM}$ Tris- $\mathrm{HCl}, \mathrm{pH} 7.5,1 \mathrm{mM}$ dithiothreitol, allowed to hybridize 10 minutes at $37^{\circ} \mathrm{C}$, and 3 units of RNase $\mathrm{H}(1.5 \mu \mathrm{L}, \mathrm{BRL})$ were added. Incubation continued for 30 minutes. Cleavage was terminated by the addition of $0.885 \mathrm{~mL}$ of buffer $\mathrm{C}$, followed by incubation for 10 minutes at $68^{\circ} \mathrm{C}$.

Step 3 (apoll mRNA purification). Eighty microliters of $5 \mathrm{M} \mathrm{NaCl}$ was added, the material applied to an oligo(dT) cellulose column, and the flow-through reapplied to the column for a total of five cycles. The unbound material, as well as two $1 \mathrm{~mL}$ washes with binding buffer, was pooled as the apoII mRNA fraction. Bound mRNA was washed and eluted from the column as in Step 1. RNA fractions were purified by phenol/chloroform extraction and ethanol precipitation.

The Northern blot in Figure 1A shows the distribution of apoII mRNA in the flow-through $(F)$ and bound (B) fractions from the oligo (dT) cellulose column after digestion with RNase H. Whereas undigested apoII mRNA is recovered entirely in the bound fraction (lanes a and b), with increasing concentrations of RNase H, apoII mRNA is found either partly in the bound

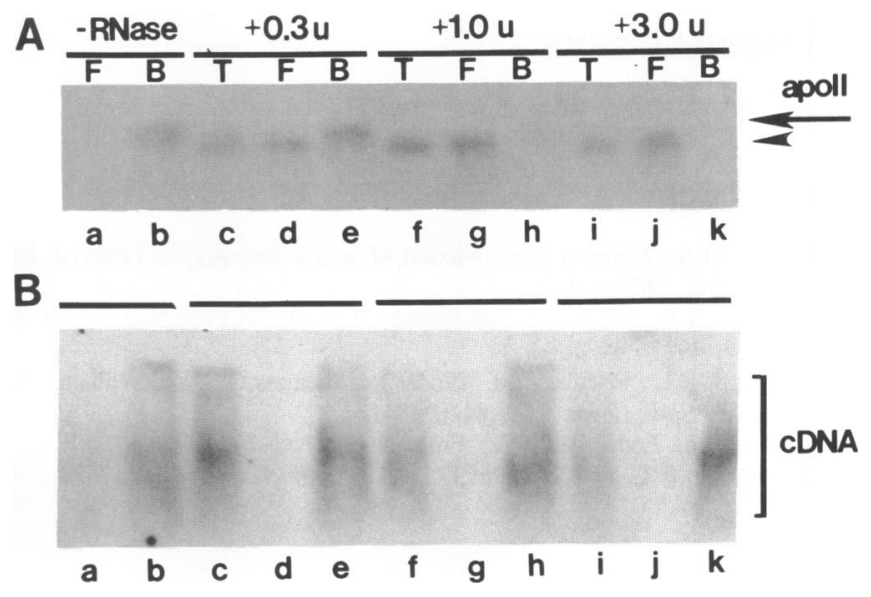

Figure 1. ApoII mRNA can be purified in the poly $\mathrm{A}^{-}$fraction after $\mathrm{RNase} \mathrm{H}$ hydrolysis. Oligonucleotide hybridization and $\mathrm{RNase} \mathrm{H}$ hydrolysis was performed on total liver RNA, and the results were assessed by Northern blot analysis (5). Panel A is Northern analysis of apoII mRNA. Panel B is Northern analysis of total non-estrogen induced mRNA. The uniformly labelled probe for apoII was made as described (1). The control cDNA probe was ${ }^{32} \mathrm{P}$-labelled oligo(dT)primed cDNA from non-estrogen treated rooster liver RNA, and thus did not contain apoll sequences (5). PolyA ${ }^{+}$RNA was incubated in the absence of RNase $H$ (lanes $a$ and $b$ ), or in the presence of 0.3 units (lanes $c-e$ ), 1.0 unit (lanes $f-h$ ), or 3.0 units (lanes $i-k$ ) of RNase H. Lanes $c, f$ and $i$ represent total RNA after RNase $\mathrm{H}$ incubation (T); lanes $\mathrm{a}, \mathrm{d}, \mathrm{g}$ and $\mathrm{j}$ are RNA from the flow-through fraction (F), and lanes $b, e, h$ and $k$ from the bound fraction (B) after oligo(dT) cellulose chromatography. The arrow indicates full-length and the arrowhead indicates cleaved apoII mRNA; the bracket (cDNA) indicates nonestrogen induced mRNAs.

\footnotetext{
* To whom correspondence should be addressed

${ }^{+}$Present address: Department of Molecular Biology, Princeton University, Princeton, NJ 08544-1014, USA
} 
and flow-through fractions (lanes $\mathrm{d}$ and $\mathrm{e}$ ), or completely in the flow-through fraction (lanes $\mathrm{g}, \mathrm{h}, \mathrm{j}$, and $\mathrm{k}$ ). Thus digestion with $\mathrm{RNase} \mathrm{H}$ and oligo $\mathrm{V}$ is efficient in cleaving the poly(A) tail from apoII mRNA. To determine the specificity of RNase $H$ digestion, a parallel Northern blot was probed with total cDNA prepared against RNA from the liver of a rooster that was not estrogentreated. This cDNA represents the spectrum of liver mRNAs but does not contain apoII mRNA-specific sequences (5). As shown in Figure 1B, the total cDNA probe detected a broad size spectrum of mRNAs in the bound fraction (lanes $e, h$, and $k$ ) but showed no hybridization to the flow through fraction (lanes $\mathrm{d}, \mathrm{g}$, and $\mathrm{j}$ ) from the oligo (dT) cellulose columns irrespective of the RNase $\mathrm{H}$ treatment. Identical results were seen in experiments in which a cDNA for chick apoA-I was used as a non-apoII mRNA probe (data not shown). Therefore, oligonucleotide-directed RNase $\mathrm{H}$ digestion selectively shifted apoII mRNA to the flow-through fraction while other mRNAs are retained in the bound fraction.

ROMP affords a simple, efficient, and rapid purification of apoII mRNA. This technique should be applicable to the purification of any polyadenylated $\mathrm{mRNA}$ for which the sequence adjacent to the poly(A) tail is known and for which the sequence is accessible for hybridization. A significant advantage of ROMP as compared to hybrid-selection (2) is that it is very rapid and avoids prolonged exposure to elevated temperatures and formamide typical of hybrid-selection. In addition, ROMP can be scaled up easily to purify larger amounts of mRNA as might be needed for structural analyses of cap structures or other posttranscriptional modifications of the mRNA.

\section{ACKNOWLEDGEMENT}

Supported by NIH award DK 18171.

\section{REFERENCES}

1. Gordon,D.A., Shelness,G.S., Nicosia,M. and Williams,D.L. (1988) J. Biol. Chem. 263, 2625-2631.

2. Ricciardi,R.P., Miller,J.S. and Roberts,B.E. (1979) Proc. Natl. Acad. Sci. USA 79, 4927-4931.

3. Hwang,S.-P.L., Eisenberg,M., Binder,R., Shelness, G.S. and Williams,D.L. (1989) J. Biol. Chem. 264, 8410-8418.

4. Aviv,H. and Leder,P. (1972) Proc. Natl. Acad. Sci. USA 69, 1408.

5. MacDonald,C.C. and Williams,D.L. (1992) Biochemistry 31, 1742-1748. 